\title{
Prostate Cancer Patient Reported Outcome After Cyberknife Robotic Radiosurgery
}

\author{
Sebastian A Exner*, Felix K Behrens and Fabian Fehlauer \\ Strahlenzentrum and Cyberknife Center Hamburg, 22419 Hamburg, Germany \\ *Corresponding author: Sebastian A Exner, Felix K Behrens, Fabian Fehlauer, Strahlenzentrum and Cyberknife Center \\ Hamburg, 22419 Hamburg, Germany
}

\begin{tabular}{l}
\hline ARTICLE INFO \\
\hline Received: 幽 August 14, 2020 \\
Published: 幽 September 01, 2020 \\
\hline
\end{tabular}

Citation: Sebastian A E, Felix K B and Fabian F. Prostate Cancer Patient Reported Outcome After Cyberknife Robotic Radiosurgery. Biomed J Sci \& Tech Res 29(4)-2020. BJSTR. MS.ID.004875.

Keywords: Cyberknife; Prostate Cancer; PRO-CTCAE; Patient Reported Outcome; Side Effects

Abbreviations: PC: Prostate Cancer, IPSS: International Prostate Symptom Score, HRQOL: Health-Related Quality of Life, PSA: Prostate Specific Antigen

\section{ABSTRACT}

Purpose: The optimal management of localized Prostate Cancer (PC) should take account consideration of patient and clinical risk factors, as well as patient preferences. The objectives of this cohort study of men with newly diagnosed localised PC were to document side effects with the International Prostate Symptom Score (IPSS), International Consultation on Incontinence Questionnaire Short Form (ICIQ-SF), International Index of Erectile Function Questionnaire (IIEF-5) and as well Patient-Reported Outcomes version of the Common Terminology Criteria for Adverse Events Questionnaire (PRO-CTCAE) following radiosurgery with the Cyberknife.

Materials and Methods: In this cohort analysis, 20 patient with localized prostate cancer were analyzed who received Cyberknife radiosurgery (5 x 7 Gy) and completed the IPSS (1-23), ICIQ-SF (0-17), IIEF-5 (6-24) and the German validated PRO-CTCAE questionnaires.

Results: Mean IPSS score was 6.9 (mild symptomatic), mean ICIQ-SF score was 3.3 (mild impairment of incontinence), mean IIEF-5 score was 17.0 (mild erectile dysfunction). The highest score at PRO-CTCAE was for urinate frequently (one patient, 5\%), achieve and maintain erection (one patient, 5\%), ejaculation problems (two patients, $10 \%$ ) and decreased libido (one patient, 5\%). There was no significant difference at follow-up period or treated prostate volume (F/U: $>1$ vs. $<1$ year; Volume ml: $>64$ vs. < 64). Local control and overall survival were $100 \%$. No patient developed metastasis after radiosurgery. None of our patients died until now.

Conclusion: Robotic Cyberknife radiosurgery for localized prostate cancer shows good local control and overall survival with a very mild side effect profile reported by patients.

\section{Introduction}

The optimal management of localized prostate cancer (PC) should take account consideration of patient and clinical risk factors, as well as patient preferences. Because of the high survival for localized prostate cancer [1], the long-term effects on HealthRelated Quality of Life (HRQOL) are possibly the most important base for the therapy decision [2,3]. Well-documented reports of HRQoL effects are important in particular for patients to make well informed and evidence-based treatment decisions. Patientreported outcome (PRO) is the direct report from a patient perspektive about the effect of disease or treatment that has not been interpreted by anyone else and can be easily understood from patient perspective [4]. Guidelines unfortunately do not serve the increasing interest in the potential relationship between treatment side effects and treatment decision [5]. This interest is linked to the shared decision-making paradigm, in which a "good" treatment choice is defined as one that fits the patients' values and preferences [6].

Recently, there has been a change toward the use of patientreported outcomes (PROs), defined as the unfiltered direct report of a given symptom toxicity by a patient, and considered to be the 
"gold standard" for the capture of symptomatic adverse events [7] This change has been led by the release of the 2009 United States Food and Drug Administration (FDA) Guidance for Industry on the Use of PRO Measures in Medical Development to Support Labeling Claims [8], which subsequently led to the NCI initiative to develop a PRO version of the CTCAE (PRO-CTCAE) that will be used in future U.S.-based clinical trials in oncology [9]. The objectives of this cohort study of men with newly diagnosed localized PC were to evaluate patient-reported outcome and side effects with IPSS, ICIQ-SF, IIEF-5 and PRO-CTCAE questioner following Cyberknife radiosurgery.

\section{Materials and Methods}

The observational, retrospective, monocenter study included 20 patients with histologically confirmed localized prostate cancer treated with the Cyberknife ${ }^{\circledR}$ System (Accuray) treated after fiducial implants with 5 fractions of 7.0 Gy (35 Gy, $70 \%$ isodose, Figure 1) every second day (treatment protocol according PACE-B study [10]). This type of stereotactic body radiotherapy (SBRT) is well established and acknowledged by international guidelines $[11,12]$. Patients who were treated between august 2012 and March 2020, were included in the analysis. Patients had newly diagnosed clinically localised PC (cT1-2 and/or Gleason 6-7, Prostate-Specific Antigen [PSA] $<20 \mathrm{ng} / \mathrm{ml}$ ). All patients had to complete IPSS, ICIQSF, IIEF-5 and the PRO-CTCAE questionnaire. The questions in the IPSS questionnaire were as follows: question (Q)1, incomplete emptying; Q2, frequency; Q3, intermittency; Q4, urgency; Q5, weak stream; Q6, straining; Q7, nocturia; Q8, constancy and is utilized to measure the severity of lower urinary tract symptoms [13] The ICIQ was developed in the early 2000s to promote use of an internationally uniform set of questionnaires [14]. The ICIQ-SF consists of 3 scored items which evaluate the frequency, volume of leakage, and overall impact of incontinence. The overall score ranges from 0 to 21 , with greater values indicating increased severity.
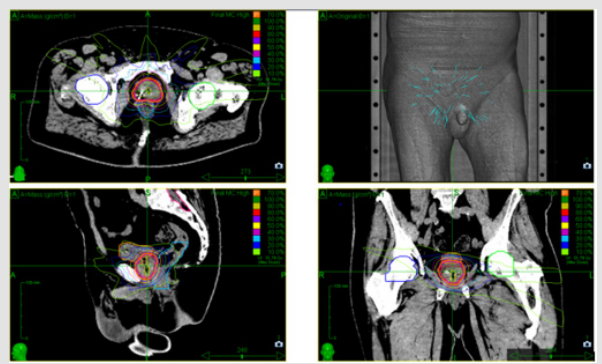

Figure 1: Example of a Cyberknife prostate iso-dose distribution.

Erectile function was prospectively assessed by a validated self-administered questionnaire IIEF-5. This questionnaire is the simplified version of 5 items of the IIEF questionnaire, which was developed by Rosen in 1997 [15]. It is recommended as a criterion of effectiveness in clinical studies on ED. It enables to classify patients into 5 classes such as: normal EF: > 21; mild ED: 17-21; mild to moderate ED: 12-16; moderate ED: 8-11; severe ED: < 8. In total, 75 symptomatic toxicities (119 PRO-CTCAE items), corresponding to the symptomatic adverse-events profile associated with the regimens commonly used for prostate cancer treatment were selected. Patients reported symptoms on a 5-point scale. The IPSS, ICIQ-SF, IIEF-5 and PRO-CTCAE were used to evaluate patient-reported disease-specific function. Patients were treated at Strahlenzentrum Hamburg and completed questionnaires at different time points after treatment. To limit study dropouts and missing data, respondents were offered to re-call or e-mail the authors for assistance, and patients received a telephone reminder 3 week after the questionnaire was sent. Study retention rates were $100 \%$ at three months.

\section{Results}

A total of 20 men were analyzed and completed the complete questionnaire and at point after therapy (median age, 73 [57-92] years). Median Age at time of therapy was 69.15 (54-79) years. Median follow-up for was 4.15 (0.5-8) years. Median initial PSA was $8.32 \mathrm{mg} / \mathrm{ml}(0,5-33)$. Median post treatment PSA was $0.58 \mathrm{mg} / \mathrm{ml}$ (0.1-4.6). Median volume of the treated volume with radiosurgery was $63.5 \mathrm{ml}$ (26-125). Mean Score of IPSS was 6.9 (1-23). A Score of 6.9 correlates to mild symptomatic. Mean Score of ICIQ-SF was 3.3 (0-17). A score of 3.3 shows a mild impairment of incontinence. Mean Score of IIEF-5 was 17.0 (6-24). A score of 17 shows only mild erectile dysfunction. The highest score at PRO-CTCAE was for urinate frequently (one patient, $5 \%$ ), achieve and maintain erection (one patient, 5\%), ejaculation problems (two patients, 10\%) and decreased libido (one patient, 5\%). There was no significant difference if the treatment was more or less than 1 year ago. There was no significant difference if the treated volume was greater than $64 \mathrm{ml}$ or less (Table 1),

Table 1.

\begin{tabular}{|c|c|c|}
\hline \multicolumn{3}{|c|}{ Results } \\
\hline Number of Patients & 20 & \\
\hline Age at follow-up & Mean: 73,25 years & From 57 - 92 years \\
\hline Age at therapy & Mean: 69,15 years & From 54-79 years \\
\hline initial PSA (0,5 - 33). & Mean: 8,32 mg/ml & From 0,5 -33 mg/ml \\
\hline post treatment PSA & Mean: 0,58 mg/ml & From 0,1- 4,6 mg/ml \\
\hline Follow up time & Mean: 4.1 years & From 0.5 - 8 years \\
\hline $\begin{array}{c}\text { Median volume } \\
\text { Prostate }\end{array}$ & Mean: 63,5 ml & From 26- 125 ml \\
\hline $\begin{array}{c}\text { Response to } \\
\text { questionnaires }\end{array}$ & $100 \%$ at three months & \\
\hline
\end{tabular}




\begin{tabular}{|c|c|c|}
\hline Local Control & $100 \%$ & \\
\hline Overall Survival & $100 \%$ & \\
\hline IPSS & Mean: 6,9 (mild) & Score: $1-23$ \\
\hline ICIQ-SF & Mean: 3,3 (mild) & Score: $0-17$ \\
\hline IIEF-5 & Mean: 17,0 (mild) & Score: $6-24$ \\
\hline
\end{tabular}

Local Control and Overall Survival was $100 \%$ and no patient developed metastasis after radiosurgery. None of the patients died until now.

\section{Discussion and Conclusion}

Using this approach (Cyberknife, SBRT), long-term data with more than 10 years of follow-up are promising and show a biochemical freedom from recurrence of $>90 \%$ for low and intermediate-risk prostate carcinomas with significantly less than $1 \%$ local recurrences. The effectiveness (PSA control) of the radiosurgery was also with longer follow-up periods persistently very high with low toxicity. In particular, the late toxicity appears to be lower than with surgery or conventional external radiation. Recently published results show slight side effects (grade 2) for SBRT ( 5 treatments) below $5 \%$ in the urogenital area (GU) and below $2 \%$ in the gastrointestinal tract (GI) with very rare serious side effects (grade 3) of below 1\% [10]. A German multicenter study using this Cyberknife approach is open to confirm existing international data for the national recommendations regarding long term effects (ClinicalTrials.gov NCT03795337). In this limited cohort analysis, Cyberknife radiosurgery for localized prostate cancer confirms low adverse effect profiles determined by the patients themselves with excellent local control and overall survival. The low incidence of toxicity in the PRO-CTCAE questionnaire shows a very acceptable and low adverse effect profile.

As well as with the good results of well-established scoring systems like IPSS, ICIQ-SF and IIEF-5. Since curative therapy options in man with localized prostate cancer (surgery: robotic or conventional radical prostate resection; radiotherapy: brachytherapy, conventional irradiation or radiosurgery) remain iso- effective and with regard to recent publications [16], it is very important to choose a treatment strategy with a low impact on the health-related quality of life and high cure rate. Furthermore, a short treatment interval ( 5 treatments only), minor side effects, good quality of life, less follow-up therapies, no absence from family and work, no hospitalization, no rehabilitation after therapy and increasing reports might be cumulative reasons to decide for Cyberknife treatment by man with localized prostate cancer acknowledged by their families, international societies and health care insurance companies.

\section{References}

1. Hamdy FC, Donovan JL, Lane JA, Richard M Martin, Jon Oxley, et al. (2016) 10-Year outcomes after monitoring, surgery, or radiotherapy for localized prostate cancer. N Engl J Med 375: 1415-1424.

2. Donovan JL, Hamdy FC, Lane JA (2016) Patient-reported outcomes after monitoring, surgery, or radiotherapy for prostate cancer. N Engl J Med 375: $1425-1437$.

3. Lardas M, Liew M, Van den, Bergh RC, De Santis M, et al. (2017) Quality of life outcomes after primary treatment for clinically localised prostate cancer: a systematic review. Eur Urol 72(6): 869-885.

4. Talcott JA, Clark JA, Manola J, Mitchell SP (2006) Bringing prostate cancer quality of life research back to the bedside: translating numbers into a format that patients can understand. J Urol 176(4): 1558-1564.

5. Hoffman RM, Lo M, Clark JA (2017) Treatment decision regret among long-term survivors of localized prostate cancer: results from the prostate cancer outcomes study. J Clin Oncol 35(20): 2306-2314.

6. Christie DRH, Sharpley CF, Bitsika V (2015) Why do patients regret their prostate cancer treatment? A systematic review of regret after treatment for localized prostate cancer. Psychooncology 24(9): 1002-1011.

7. Chen RC, Chang P, Vetter RJ, Bryce B Reeve, Howard M Sandler, et al. (2014) Recommended patient-reported core set of symptoms to measure in prostate cancer treatment trials. J Natl Cancer Inst 106: 1-7.

8. (2006) US Department of Health and Human Services FDA Center for Drug Evaluation and Research., U.S. Department of Health and Human Services FDA Center for Biologics Evaluation and Research., U.S Department of Health and Human Services FDA Center for Devices and Radiological Health. Health Qual Life Outcomes 4: 79.

9. Dueck AC, Mendoza TR, Sandra A Mitchell, Bryce B Reeve, Kathleen M Castro, et al. (2015) Validity and Reliability of the US National Cancer Institute's Patient-Reported Outcomes Version of the Common Terminology Criteria for Adverse Events (PRO-CTCAE). JAMA Oncol 1(8): 1051-1059.

10. Brand, Douglas HDodds D (2009) Intensity-modulated fractionated radiotherapy versus stereotactic body radiotherapy for prostate cancer (PACE-B): acute toxicity findings from an international, randomised, open-label, phase 3, non-inferiority trial. The Lancet Oncology 20(11): 1531-1543.

11. NCCN Guidelines Version 2.2020 Prostate Cancer.

12. Martin G, Sanda MD, Ronald C, Chen et al. (2017) American Urological Association (AUA) / American Society for Radiation Oncology (ASTRO) / Society of Urologic Oncology (SUO), Approved by the AUA Board of Directors April.

13. Barry MJ, Fowler FJ, WK Mebust, AT Cockett (1992) The American Urological Association symptom index for benign prostatic hyperplasia. J Urol 148: 1549-1557.

14. Donovan JL, Badia X, Corcos J (2002) Symptom and quality of life assessment. In Abrams P, Cardozo L, Khoury S, Wein A eds, Incontinence, ( $2^{\text {nd }}$ edn) Chapt. 6. Plymouth, UK: Health Publication Ltd pp. 267-316.

15. Rosen RC, Riley A, Wagner G, Osterloh IH, Kirkpatrick J, et al. (1997) The international index of erectile function (IIEF): a multidimensional scale for assessment of erectile dysfunction. Urology 49(6): 822-830.

16. Hoffman KE, Penson DF (2020) Patient-Reported Outcomes Through 5 Years for Active Surveillance, Surgery, Brachytherapy, or External Beam Radiation with or Without Androgen Deprivation Therapy for Localized Prostate Cancer. JAMA 323(2): 149-163.

\section{Conflict of Interest}

None. 
ISSN: 2574-1241

DOI: 10.26717/BJSTR.2020.29.004875

Sebastian A Exner. Biomed J Sci \& Tech Res

(c) (P) This work is licensed under Creative

Submission Link: https://biomedres.us/submit-manuscript.php

$\begin{array}{ll}\text { BIOMEDICAL } & \text { Assets of Publishing with us } \\ \text { RESEARCHES } & \text { Global archiving of articles } \\ \text { - Immediate, unrestricted online access }\end{array}$

